\title{
ANAESTHESIA AND MEDICAL EDUCATION
}

\author{
EDWARd C. Cockings, M.D., F.R.C.P.(C), AND \\ GoRDON M. WYANT, C.D., F.F.A.R.C.S., F.R.C.P.(C) ${ }^{*}$
}

IT IS THE PURPOSE OF THIS PAPER to examine in some detail the role of anaesthesia in medical education at the undergraduate, graduate, and postgraduate levels. A review of this nature seems particularly timely since there is at present much discussion and much soul searching in an attempt to determine what is relevant in present-day undergraduate medical education. It is becoming clear also that all may not be well with specialty training.

We live in a time of ferment in medicine, as evidenced by near-revolutionary experiments with the curriculum by many medical schools in an attempt to keep pace with the expanding body of knowledge, the accelerating trend towards specialization and the replacement of the individual by the team approach to patient care. There is also increasing activity on the part of governments and society to provide adequate physician coverage, both quantitatively and qualitatively, in areas in which there are critical deficiencies. In this connection it is probably significant that, at a time when large sums of public money are being withdrawn in the United States from research that is not directly applicable to the benefit of society, increasing sums are being provided for the establishment of new training facilities, for the improvement of existing ones, and for research and residency training programmes to those fields in which there is a critical manpower shortage. Anaesthesia is one of these.

Despite a study sponsored by the Canadian Anaesthetists' Society, it is still not clear how critical the manpower situation in anaesthesia really is in Canada, after factors such as distribution and opportunity are considered. In any case the situation is far from ideal. Hence it must be the object of all those entrusted with recruitment and training of future anaesthetists to make the specialty attractive to the young physician. Simultaneously, attempts must be made to arouse public and professional awareness of the contributions the anaesthetist can and should make to total patient care by virtue of his special skills and training. These obligations, however, can be discharged only if sufficient manpower is available to cover this broader field. In this connection also it must be realized that, even apart from an increase in numbers, a constant supply of young men is required in any case to rejuvenate the specialty and keep it strong, virile, and aggressive.

\section{Undergraduate Training}

It is probably true to say that the social and economic rewards of the practice of medicine are known to the student prior to his entrance into medical school, although

"From the Department of Anaesthesia, University of Saskatchewan, and University Hospital, Saskatoon, Saskatchewan. 
his concept of medicine might be somewhat idealized. It is probably equally true that the vast majority of freshmen in medicine are uncommitted as to the kind of career they wish to pursue following graduation. Therefore to a large extent the choice of the student of a particular discipline of medicine will be related tc his exposure during the time of training and a recognition of the field which will give him the greatest professional satisfaction. To be relevant to the undergraduate, anaesthesia must appeal to him as contributing significantly to patient care. If he has the impression that the anaesthetist is a servant of the surgeon, available at his beck and call to fulfill a technical function in the operating room and no more, and oblivious to the patient's specific needs as a human being, few if any students of significant calibre will feel that their life's work should be spent in the specialty.

If one is to be able to appeal to the undergraduate, therefore, anaesthesia must be given time within the medical curriculum to show by word and by deed what its contributions are to the overall welfare of the patient. This involves hard bargaining with those charged with determining the contents of the curriculum. To be effective in these negotiations the anaesthetist must have a very clear awareness of what his contribution to the overall education of the student really is. At a time when all disciplines in medicine must reappraise their cherished concepts of teaching everything to everybody, the anaesthetist will get consideration only if he can prove that he is able and willing to teach those concepts in his field which are indispensable to the general education of a physician, and if he accepts, as other disciplines have had to accept, the fact that detailed knowledge in any field can only be gained by postgraduate study. He must be able to convince his peers that he has a unique contribution to make in certain areas such as the management of the unconscious patient, the maintenance and restoration of adequate cardio-respiratory function, and fields of applied physiology and pharmacology relating in particular to the cardio-respiratory, renal and endocrine systems.

While lectures in pharmacology may be given by the anaesthetist early in the curriculum, the golden opportunity to demonstrate to the undergraduate the relationship between anaesthesia and patient care is presented in the later years. Lectures and seminars should stress principles and broad concepts. In the operating room the student must be shown that while, for the good-risk patient who is being anaesthetized for an elective minor operation, the contact of the anaesthetist might appear somewhat fleeting, this must not be the case with a poor-risk patient. A good-risk patient can be used to demonstrate, under close supervision, the techniques of anaesthesia and in particular the effect of drugs. The demonstration of these skills, however, should not be allowed to obscure the anaesthetist's role as a broadly trained physician, involved in pre- and postoperative care and with authority to influence these activities. In practice every opportunity should be taken to demonstrate problem cases in the intensive care unit, both on surgical and non-surgical patients. The individual anaesthetist sees probably more pathophysiology in his working day than most other medical practitioners, and it is essential that this unique opportunity be exploited to the utmost in the teaching of the undergraduate.

Although results of this exposure are not immediately discernible, they will 
come to fruition in later years when after his internship and perhaps a few years in general practice the student returns to his parent department for specialist training.

\section{ROTATING INTERNSHIPS}

The rotating internship as we have known it in North America certainly is going to be phased out during the next few years. Its place has been taken in many schools by the fourth-year student internship, so that following graduation the majority of young physicians will elect a year of straight or mixed internships. Since the classical rotating internship still will be available for a period of years, it remains appropriate at this time to describe our experiences and philosophy regarding it and to delineate how in our opinion it should differ from the new finalyear student internship. Both of these have in common the fact that, in a few schools only, anaesthesia is a compulsory subject, while in the majority anaesthesia is elective. We have had experiences with both the elective and the compulsory rotation. Much could be said for an obligatory period of one month on the anaesthesia service, since surely every physician, whatever his future calling, should be able to deal effectively with states of unconsciousness and with resuscitation even if he is never called upon in his professional life to administer an anaesthetic. On the other hand, if the subject is elective, the approach of the intern is a much more positive one since he is there of his own volition, having realized that he can learn something useful. It is striking how many of those who have entered general practice have returned for further training to become more proficient. Indeed, if one succeeds in convincing the tyro of the pitfalls and dangers of anaesthesia so that he either does not tackle it at all or else seeks further training, the month on the anaesthesia service has been well spent in the interests of patient safety.

The rotating intern who was a graduate of our own school had in his student days been exposed to a clerkship in anaesthesia, and thus presented a problem somewhat different from that of the student intern with whom we deal now. It had been the intention to provide the classical intern with a fairly high volume of clinical practice on good risk patients under direct supervision of the attending staff. This constituted a degree of advanced training superimposed on his experiences as a medical student. The patients selected were those undergoing operations which the young doctor was likely to face in future rural practice. Those who did not prepare themselves for general practice but still elected anaesthesia as an optional subject at least shared with them a formal instruction in (1) the proper preoperative evaluation and work-up of patients and the unnecessary risks which could be avoided, (2) cardio-respiratory resuscitation, including airway management:, (3) the uses and abuses of intermittent positive pressure breathing, (4) the care of the seriously injured patient, (5) the use of regional techniques in the production of analgesia and the application of such techniques for the relief of acute and chronic pain, (6) a greater appreciation of the uses and abuses of a wide variety of drugs and a sense of pharmacological propriety.

It is these latter points which we are stressing now in our fourth-year student intern program. Anaesthesia at the present can be taken by the student as an 
option on the surgical quarter or the medical quarter or as one of the electives. It is interesting that one or two students have chosen anaesthesia both on the medical and surgical quarter. Such a high proportion of the class have opted for anaesthesia that serious consideration is being given now to making anaesthesia a compulsory service, if for no other reason than to lessen the impact which the high proportion of options has on the major services from which these people must be released for a full month. While the fourth-year student intern does get his share of time in the operating room, the emphasis has been shifted from this to a seminar type of instruction since his experience is no longer based on a preceding clerkship, and also in order to present him with the many facets of anaesthesia outside the operating room, and impress him with the anaesthetist as a physician participating in the total care of the patient in his own right.

In this connection it may be well to recall that the AMA Council on Medical Education and Hospitals in 1965 considered "that resources of the Department of Anaesthesia [should] be fully utilized in training interns in that such an experience will contribute significantly to many careers in medicine."

\section{Resment Thaining}

While the motivation to enter specialist training varies from resident to resident, one must assume that each wishes to emerge from four years of training as something more than a competent technician. Hence training in the technical skills and the development of clinical judgment and experience must be balanced judiciously by adequate teaching of the basic sciences and the theoretical background of the specialty. In an attempt to achieve this goal, one must avoid the temptation of appointing residents for the mere purpose of "filling slots" in the establishment, based solely on service requirements. Only those persons should be accepted whose background, experiences, or attitude would indicate that they are fitted for training and that they have entered the specialty with the proper motivation. After assuming their duties candidates must demonstrate their willingness and ability to progress both in knowledge and in skill to such a degree that there is a reasonable chance that they will reach standards acceptable at least for certification by the Royal College. If for one reason or another it becomes clear that this goal cannot be achieved, the resident's training must be discontinued. This is a hard decision to make and must not be made lightly, but only after mature consideration. If possible it should be by unanimous consensus or at least by agreement of the vast majority of the teachers involved. While discontinuance of a resident is a traumatic experience for both parties, it is preferable to the wasting of four years of an individual's life when his chances of becoming an established specialist are practically non-existent.

At the completion of his training the resident must be clinically competent. This is best achieved by exposing him to as many clinical situations as possible and by using a system of graded responsibility. No junior resident should be confronted with a case well beyond his capabilities simply because the anaesthetic has to be given at this particular time and he is the only one available. All anaesthetics should be supervised. Supervision must be constant but only enough con- 
tinuous physical presence of the instructor should be used as is necessary to ensure the safety of the patient. Only in this way will the student, at the completion of his training, be prepared to assume independent responsibility. The speed with which graded responsibility can progress will vary from resident to resident on a strictly individualized basis.

There must be insistence on the highest standard of preoperative work-up, anaesthetic care, and postoperative follow-up. There is no doubt that the high standards demanded in preoperative preparation of the patient, compromised only by the urgency of the operation, have led not infrequently to confronttaion with surgeons who "want to get on with the job." It is our belief that in a teaching hospital one should attempt to approach the ideal of medical practice as a basis for training. When his trade has been learned under near-ideal conditions, the young specialist will be able to recognize more clearly how far he can go in "cutting corners" when he must face the realities of life as a clinician with its economic implications.

In balancing clinical experience with didactic teaching, the need for spare time must not be forgotten. Some of this will be required for home study, some for relaxation. The provision of such spare time presents no difficulty in the early years of training, but becomes somewhat more difficult in the final year when one wishes the senior residents to gain as much experience as possible in the handling of poor-risk, emergency patients or unusual situations. Unfortunately this is also the time of the highest demand for study time, especially because so much of it has been wasted in the early years when the urgency to "hit the books" had been less compelling. In an attempt to solve this dilemma we offer our residents low clinical load appointments between the termination of their formal training and the beginning of specialty examinations later in the year.

At this point it would seem advisable to discuss the role of internal medicine in the training of the anaesthetist. We believe that the ideal time to take this training is in the second year when the resident has developed some awareness of those aspects of internal medicine which will be of greatest value to him as a future anaesthetist and yet has not advanced to a stage where being seconded to another service might constitute an interruption of his path towards specialist status. Without exception, the resident when he returns from internal medicine is a wiser and more mature physician and an infinitely more useful member of the department. Indeed he is now the budding medical consultant to the surgical team, a position which hopefully he will occupy in later life. We in Canada are unique in our emphasis on internal medicine and in considering our specialty as a branch of it. In doing so we have created for ourselves a status vis- $d$-vis the internist which one would be hard-pressed to find to the same extent in any other country.

As for didactic teaching, it has been our philosophy to stimulate our residents to undertake reading in the very subjects which are being presented to them or which they themselves are presenting in various kinds of seminars held regularly during the week. One should avoid covering every subject in all its ramifications so that all the student need do is regurgitate what he has been told, without the need for independent thought, logical reasoning, and initiative. It is essential that 
different points of view be presented by the teaching staff to stimulate discussion, interest, and curiosity. This may be confusing to the new resident but it is essential as an educational tool in the creation of independently thinking individuals. We believe spoon-feeding is lethal to this thinking process and thus to the development of a first-class consultant.

There are advantages and disadvantages to the policies of the various licensing bodies. It is unfortunate that candidates in specialties often view the acquisition of knowledge as a means of satisfying their examiners. In this they may be partially frustrated since there is no clear definition by the examining bodies of either the kind or the bounds of knowledge demanded of them. The delineation of set curricula would seem to be much overdue. It is gratifying that at least in anaesthesia an attempt to do so is in its early stages, owing to the initiative taken by the university department heads.

Whether or not a resident undertakes research should be left to the individual candidate, as should the kind and level of this research. There is no virtue in forcing it on someone whose essential inclination is clinical. However, opportunities must be made available for those who wish to pursue some research for its own sake or to satisfy their own curiosity on sorne point which intrigues them.

\section{Continuing Education}

It is now generally conceded that continuing education is important in all walks of life. How it is to be achieved, however, and the effectiveness of the various techniques available are matters for debate. If optimal patient care is to be achieved, the physician must continue to study and learn. This of course applies equally to the general practitioner and to the specialist.

Education seems to imply a course of instruction and a programme of study. However, there are many well-educated individuals who never have had a course of instruction; others attend courses but do not benefit from them. Therefore it would appear that attempts at continuing education must take into consideraion the motivation of the individual physician. Some perhaps have never learned the process of acquiring knowledge without the threat of impending examinations, while others may feel that their original knowledge, supplemented by the evergrowing experience of practising medicine, is sufficient for all purposes. It is the latter individual who is difficult to reach since he does not recognize the extent to which he has fallen behind. He cannot be reached by published papers if he does not read the journals, or by presentations at scientific meetings which he does not attend.

For the interested physician, whether specialist or general practitioner, there should be little problem in keeping up with newer developments in his field of activity. He can do so by reading periodicals or monographs, by keeping in frequent contact with specialists in his own and in related fields, by attending various conferences at a local, national, and international level, and finally by making use of postgraduate refresher courses.

A physician in any specialist field of practice should not be overwhelmed by 
the literature: he should have learned to sort the wheat from the chaff. The general practitioner, on the other hand, may well find himself in a much less fortunate position. However, he has available to him an ever-increasing number of abstracting services which attempt to present a representative cross-section of knowledge.

While courses for specialists can be arranged in such a way as to present very detailed information pertaining to very selected fields, those for general practitioners must be much more general in outline. The problem with such courses in anaesthesia is that they are attended by physicians whose level of training and experience varies widely. The exposure possible to either theoretical or practical knowledge during the short time available is quite inadequate and indeed may lead to a poorer practice engendered by overconfidence or half truths gained from misinterpretation of what has been presented in far too sketchy a form. One wonders whether it would not be much preferable to substitute for the three- or four-day courses for general practitioners an externship in university-affiliated hospitals where each course could be individualized in scope, depth, and duration to provide the physician with that knowledge and skill which best fits into his type of medical practice. Where this has been tried the experience thus gained has been useful by and large and has been appreciated by those who have availed themselves of the opportunity.

\section{SUMMARY}

A concept is presented of the author's philosophy of the teaching of anaesthesia at all levels of medical education: what the aims should be, and how best to achieve them. The views expressed are those of the authors. Some teachers or trainees may feel that the wrong emphasis has been placed on the wrong subjects or that they cannot accept some of the views expressed. There are of course many ways to skin a cat, as long as good candidates are attracted in adequate numbers into the specialty. Provided the final product is first-class, any approach is acceptable. Medical education is not static; changes must be made continuously at all levels to make teaching relevant to the requirements of society for clinical, educational, and research purposes.

\section{RÉsumÉ}

Les auteurs ont présenté leurs vues sur la façon d'intégrer l'anesthésie à différents niveaux de l'éducation médicale. Ils sont d'avis que, au niveau prédoctoral, au sens le plus large du mot, les élèves doivent venir en contact avec l'anesthésiste; celui-ci insistera plus particulièrement sur des aspects où il peut apporter une contribution dans l'éducation générale de l'élève. A ce moment là, il n'est pas nécessaire d'insister sur le perfectionnement en anesthésie; si l'étudiant désire faire de l'anesthésie au cours de sa pratique médicale, il faut plutôt l'inciter à suivre des cours de spécialisation postdoctoraux. Les auteurs parlent également de la place de l'anesthésie dans l'internat rotatoire et dans le séjour des étudiants dans les hôpitaux, ce qui est plus récent. 
En ce qui concerne la formation des résidents, les auteurs insistent sur l'équilibre entre l'expérience pratique à l'intérieur et à l'extérieur de la salle d'opération et l'enseignement théorique. On doit exiger que l'élève prenne une part active dans les traitements pré et postopératoires des malades et lui faire assumer des responsabilités dans les unités de "soins intensifs" : cela doit faire partie essentielle de sa formation. Une fois sa formation complétée, il ne doit pas devenir seulement un anesthésiste compétent, mais aussi le consultant médical de l'équipe chirurgicale.

Enfin, les auteurs parlent de ce que peut apporter l'anesthésiste dans l'éducation médicale permanente en médecine.

\section{REFERENCES}

1. AMA Council on Medical Education and Hospitals. Directory of Approved Internships and Residencies (1965), p. 123. 